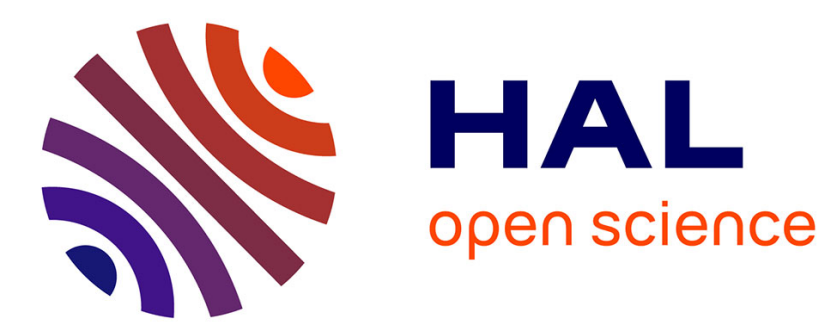

\title{
Positron Lifetime Study in Al-Li Alloys
}

F. Plazaola, N. de Diego, J. del Rio, P. Moser

\section{To cite this version:}

F. Plazaola, N. de Diego, J. del Rio, P. Moser. Positron Lifetime Study in Al-Li Alloys. Journal de Physique IV Proceedings, 1995, 05 (C1), pp.C1-119-C1-126. 10.1051/jp4:1995113 . jpa-00253549

\section{HAL Id: jpa-00253549 https://hal.science/jpa-00253549}

Submitted on 1 Jan 1995

HAL is a multi-disciplinary open access archive for the deposit and dissemination of scientific research documents, whether they are published or not. The documents may come from teaching and research institutions in France or abroad, or from public or private research centers.
L'archive ouverte pluridisciplinaire HAL, est destinée au dépôt et à la diffusion de documents scientifiques de niveau recherche, publiés ou non, émanant des établissements d'enseignement et de recherche français ou étrangers, des laboratoires publics ou privés. 


\title{
Positron Lifetime Study in Al-Li Alloys
}

\author{
F. Plazaola, N. de Diego*, J. del Rio* and P. Moser** \\ Elektrika eta Elektronika Saila, Euskal Herriko Unibertsitatea, 644 p.k., 48080 Bilbo, Spain \\ * Departamento de Física de Materiales, Universidad Complutense, 28040 Madrid, Spain \\ ** Département de Recherche Fondamentale, Service de Physique, MP, C.E.N.G., 38041 Grenoble, \\ France
}

\begin{abstract}
Light alloys such as Al-Li binary alloys are very important from the technological point of view due to their mechanical properties. The Al-rich side of the Al-Li binary alloy for Li concentrations between $5 \%$ and $25 \%$ atomic contains at room temperature a two-phase region formed by the $\alpha$ terminal solid solution and the ordered metastable $\delta^{\prime}$-phase $\mathrm{Al}_{3} \mathrm{Li}$. We present a systematic positron lifetime study for Li content below and above 5at\% (the appearance of $\delta^{\prime}$-phase) in the Al-rich side of the binary alloy to investigate the influence of $\mathrm{Li}$ content and also the influence of $\mathrm{Zr}$ addition. We also present the study of the formation and dissolution of $\delta^{\prime}$ precipitates, the recovery behaviour of an electron irradiated alloy, aging studies to monitor Li losses, and the Li influence on the nucleation of defects in quenched alloys. The technique has proved to be very sensitive to $\mathrm{Li}$-rich zones in the $\alpha$ solid solution and to the growth and dissolution of $\delta^{\prime}$ precipitates due to the high positron affinity for $\mathrm{Li}$ in an $\mathrm{Al}$ matrix.
\end{abstract}

\section{INTRODUCTION}

Al-Li based alloys are of great interest from the technological point of view due to the advantages they present in comparison to the conventional $\mathrm{Al}$ alloys used nowadays in the space industry. Up to $4 \%$ in weight $\mathrm{Li}$, every $1 \%$ in weight of $\mathrm{Li}$ added to $\mathrm{Al}$ decreases the density by about $3 \%$ and increases the elastic modulus by about $6 \%$ [1]. Moreover, the equilibrium maximum solubility of $\mathrm{Li}$ in $\mathrm{Al}$ amounts to $4.2 \%$ in weight. Therefore, the ability to reduce the density and improve the elastic modulus being quite large, these alloys have become potential materials to reduce the weight of the aircraft and consequently engine's fuel. However, the low ductility of the Al-Li alloys together with their low fracture tenacity are problems to overcome that are being studied in order to make these alloys good candidates for technological applications [2].

From the technological point of view the most important part of the Al-Li binary alloy is the Al-rich side that has two stable solid phases: the $\alpha$ terminal solid solution of $\mathrm{Al}$ with $\mathrm{Li}$ and the $\delta$ (AlLi) phase. The most important characteristic of this region is the precipitation, after quenching from the monophasic $\alpha$ terminal solid solution (above $\approx 673 \mathrm{~K}$ ) and for Li concentrations between 5 and 25 atomic\%, of the metastable $\delta^{\prime}$-phase $\mathrm{Al}_{3} \mathrm{Li}$ [3]; this is responsible for the good mechanical properties of Al-Li alloys [4]. Even though the formation and growth of the $\delta^{\prime}$-precipitates has been the subject of many investigations ([1] and references therein), little is known about the early stages of the formation of the $\delta^{\prime}$-precipitates. In fact, there is a controversy in the literature about the existence or not of a metastable precursor phase prior to the formation of the $\delta^{\prime}$-phase. Most of the experimental works directed to study the formation of the $\delta^{\prime}-$ precipitates have been carried out by using electron microscopy and/or differential scanning calorimetry. However, to the authors' knowledge, very few works have been performed by using spectroscopic techniques to study the early stages of the formation process of the $\delta^{\prime}$-precipitates. 
The positron affinity to one of the components of a binary alloy makes positron annihilation spectroscopy (PAS) a very suitable technique to study vacancy type defects or zones rich in the component for which positrons have a stronger affinity $[5,6]$. Since Li has a higher positron affinity than Al [7], the $\mathrm{Al}-\mathrm{Li}$ system is a very good candidate to be studied by PAS.

\section{EXPERIMENTAL}

The alloys presented in table 1 are the ones used in this work. According to the literature [3] $\mathrm{Li}$ is in solid solution in the alloys 1-3, although the Li content for alloy 3 lies very close to the $\delta$ ' solvus line at room temperature; for alloys 4-5 a fine dispersion of $\delta^{\prime}$ precipitates is present in the as-quenched state from high temperature [8]. In the concentrated alloy containing $\mathrm{Zr}$ an $\mathrm{Al}_{3} \mathrm{Zr}$ phase is expected, surrounded by $\delta^{\prime}$ phase domains [9].

TABLE 1.-Composition of the Al-Li Alloys studied

\begin{tabular}{lll}
\hline Alloy & Composition & Observations \\
\hline 1 & Al-1.7 at \%Li & $\begin{array}{l}\text { Prepared in the Hann-Meitner } \\
\text { Institut }\end{array}$ \\
2 & Al-3.74at\%Li & Commercial alloys supplied \\
3 & Al-4.26at\%Li-0.05at\%Zr & by Alcan \\
4 & Al-8.6at\%Li-0.04at\%Zr &
\end{tabular}

The thermal treatments were carried out under argon atmosphere and the lifetime measurements were performed by using a conventional fast system with a resolution of $260 \mathrm{ps}$ (FWHM); $10 \mu \mathrm{Ci}$ of ${ }^{22} \mathrm{NaCl}$ solution onto a thin $\mathrm{Ni}$ foil was used as a positron source. The sample surfaces were mechanically ground and chemically polished before each thermal treatment. All the samples were chemically polished prior to the lifetime measurement in order to remove the $\mathrm{Li}$ depleted zone close to the surface. The electron irradiation of alloy 5 was carried out at $20 \mathrm{~K}$ with electrons of $3 \mathrm{MeV}$ to a dose of $10^{18} e^{--} / \mathrm{cm}^{2}$.

\section{RESULTS AND DISCUSSION}

\subsection{Li influence on the annihilation parameters.}

Table 2 shows the experimental results obtained for different samples after the indicated thermal treatments. They indicate that the lifetime values in $\mathrm{Al}-\mathrm{Li}$ alloys depend on the phase diagram region to which the alloy belongs, rather than strictly depending on the Li content. The lifetime value characteristic of $\mathrm{Al}-\mathrm{Li}$ solid solution appears to be $\tau=176 \mathrm{ps}$ regardless of the $\mathrm{Li}$ content. Moving into the phase diagram region where the $\delta^{\prime}$ phase is present (i.e. Li content above roughly 5at\%) leads to an increase in the lifetime value $(\tau=181 \mathrm{ps})$. The annealing increases further the lifetime value to $\tau=189 \mathrm{ps}$. It is noteworthy that in the as-quenched state a fine dispersion of $\delta^{\prime}$ particles is to be expected in both alloys $4(q)$ and $5(q)$, whereas after the thermal treatments described in table 2 large $\delta$ ' precipitates are present in the alloys [11]. The effect of the stoichiometry on the annihilation parameters in disordered binary alloys has been already reported in several works $[12,13]$. The theoretically calculated value for bulk $\mathrm{Li}$ is $\tau=300 \mathrm{ps}[6]$; thus a stoichiometry effect would lead to a systematic increase in the lifetime with increasing Li content, which is not the case (see table 2). Moreover, the reasoning is no more valid for alloys labelled 4(a) and 5(a), where the $\delta^{\prime}$ phase is present. Therefore, the effects on the lifetime values arise from the alloy microstructure.

The positron lifetime for the alloys 1 and 2 is higher than the lifetime for bulk $\mathrm{Al}$, indicating that the presence of $\mathrm{Li}$ modifies the annihilation characteristics as expected from affinity calculations $[7,14]$. We can interpret these results as positrons annihilating in small Li rich zones that should have roughly the same structure, regardless of the Li content.

When comparing the theoretical value for the lifetime obtained for the $\mathrm{L} 1_{2}$ structure corresponding to the $\mathrm{Al}_{3} \mathrm{Li}$ metastable $\delta$ ' phase, $\tau=187 \mathrm{ps}$ [6], with the lifetime value measured in the aged alloys having a high $\mathrm{Li}$ concentration $(8.6$ and 9.9 at $\%$ ), it can be concluded that in the aged samples positrons are annihilating in saturation at the $\delta$ ' phase. 
TABLE 2.- Experimental positron lifetimes obtained after the indicated heat treatments for the Al-Li alloys shown in table 1 .

\begin{tabular}{|c|c|c|c|}
\hline Alloy & $\tau(\mathrm{ps})$ & Heat treatment & Observations \\
\hline 6NAl & $165 \pm 2$ & Annealed at $800 \mathrm{~K}$ for 5 hours & \\
\hline $\begin{array}{l}1 \\
2 \\
3\end{array}$ & $\begin{array}{l}176 \pm 2 \\
176 \pm 2 \\
183 \pm 2\end{array}$ & $\begin{array}{l}\text { Annealed } 60 \text { minutes at } 823 \mathrm{~K} \\
\text { Annealed } 60 \text { minutes at } 823 \mathrm{~K} \\
\text { Annealed } 60 \text { minutes at } 823 \mathrm{~K}\end{array}$ & $\begin{array}{l}\mathrm{Li} \text { in solid solution } \\
\mathrm{Li} \text { in solid solution } \\
\mathrm{Li} \text { in solid solution }\end{array}$ \\
\hline $\begin{array}{l}4(q) \\
5(q)\end{array}$ & $\begin{array}{l}181 \pm 2 \\
181 \pm 2\end{array}$ & $\begin{array}{l}1 \mathrm{~h} \text { at } 843 \mathrm{~K} \text { and quenched into } \\
\text { room temperature }\end{array}$ & $\begin{array}{l}\delta^{\prime} \text { phase } \\
\delta^{\prime} \text { phase }\end{array}$ \\
\hline $\begin{array}{l}4(a) \\
5(a)\end{array}$ & $\begin{array}{l}189 \pm 2 \\
189 \pm 2\end{array}$ & $\begin{array}{l}\text { As quenched from } 843 \mathrm{~K} \text { followed } \\
\text { by aging for } 1 \mathrm{~h} \text { at } 510 \mathrm{~K} \\
(4(\mathrm{a})) \text { or } 550 \mathrm{~K}(5(\mathrm{a})) \text { and } \\
\text { quenching to room temperature }\end{array}$ & $\begin{array}{l}\delta^{\prime} \text { phase } \\
\delta \text { phase }\end{array}$ \\
\hline
\end{tabular}

According to the literature [3], $\mathrm{Zr}$ promotes the formation of an $\mathrm{L}_{2}$ precipitate that gives rise to a composite particle $\mathrm{Al}_{3}(\mathrm{Zr}, \mathrm{Li})$ in which $\mathrm{Al}_{3} \mathrm{Zr}$ cores are surrounded by $\mathrm{Al}_{3} \mathrm{Li}$ envelopes. The value $\tau=189 \mathrm{ps}$ obtained for both 4(a) and 5(a) alloys shows that $\mathrm{Zr}$ has no effect on the lifetime. From these observations it can be concluded that positrons are preferentially annihilating at the $\mathrm{Al}_{3} \mathrm{Li}$ envelopes, in agreement with positron affinity data [7].

The higher lifetime value for the alloy labelled 3 as compared with the alloys 1 and 2 cannot be attributed to the presence of $\mathrm{Zr}$ according to our previous reasoning concerning alloys 4 and 5 . We rather believe that $\mathrm{Li}$ is not in completely solid solution due to the vicinity of the $\delta$ ' solvus line.

\subsection{Formation and dissolution of $\delta^{\prime}$ precipitates.}

The alloy labelled 5 was homogenised for two hours at $843 \mathrm{~K}$ and quenched to room temperature into water. The aging time at room temperature prior to starting the measurements was not higher than $24 \mathrm{~h}$. According to Hono et al. [15] extremely small $\delta$ ' precipitates are present from the as-quenched state even for very short aging periods at room temperature. Figure 1 shows the effect of isochronal annealing on positron lifetime. The annealing time was $30 \mathrm{~min}$. Each annealing was followed by quenching in room temperature water. The lifetime value of $189 \mathrm{ps}$ measured after annealing at $550 \mathrm{~K}$ agrees with the predictions of the theoretical calculations for the $\mathrm{Ll}_{2}$ structure of $\mathrm{Al}_{3} \mathrm{Li}$ and with the value obtained in the same sample after more prolonged annealing (5(a) in table 2). Therefore the value of $189 \mathrm{ps}$ can be assigned to positron annihilation from the $\delta$ ' phase. The lifetime value $175 \mathrm{ps}$, achieved at $423 \mathrm{~K}$ and at $723 \mathrm{~K}$ agrees with the one obtained in $\mathrm{Al}-\mathrm{Li}$ alloys where $\mathrm{Li}$ is in solid solution (see table 2). Therefore, taking into account that in the studied alloy, first, both the terminal solid solution $\alpha$ and $\delta$ ' small precipitates should be present at room temperature, second, the annihilation from $\delta$ ' precipitates gives a longer lifetime of 189 ps and third, there are not $\delta^{\prime}$ precipitates left at $773 \mathrm{~K}$, the value of $175 \mathrm{ps}$ has to be assigned to annihilation from the $\alpha$-phase. We interpret the lifetime decrease from $550 \mathrm{~K}$ on to the dissolution of the large $\delta^{\prime}$ precipitates grown by annealing at $550 \mathrm{~K}$.

The lifetime value obtained in the as-quenched samples, $\tau=180 \mathrm{ps}$, is longer than the value corresponding to annihilation from $\alpha$-phase, and decreases with the annealing temperature to reach the value corresponding to the $\alpha$-phase at $423 \mathrm{~K}$. This behaviour of the positron lifetime clearly indicates that at least some of the positrons are annihilating in the as-quenched alloys from a state different to the $\alpha$-phase. However, by increasing the annealing temperature, the fraction of positrons annihilating from that state decreases to vanish at $423 \mathrm{~K}$. Therefore, in the alloy annealed at $423 \mathrm{~K}$, the state from which the positrons are annihilating in the as-quenched state has disappeared or the distance between the trapping centres corresponding to that state is further away from the positron diffusion length, that in the case of Al is above $100 \mathrm{~nm}[16]$.

Similar behaviour to the positron lifetime has been observed by Differential Scanning Calorimetry [17-19]. DSC thermograms present endothermal peaks at lower temperatures than the corresponding to the dissolution temperature of the $\delta^{\prime}$ phase. Papazian et al. [18] ascribed these peaks to the dissolution of disordered $\mathrm{Li}$ clusters or G.P zones. A theoretical study of the phase diagram by the cluster variation method [20] also supported this hypothesis. However, more recently, Khachaturyan et al.[21] have 
suggested that the final microstructure of these as-quenched Al-Li alloys is a mixture of ordered $\delta^{\prime}$ precipitates in a disordered matrix. It should be noted that the diffraction patterns found in this sample and other as-quenched samples $[15,22]$, show the $\mathrm{Ll}_{2}$ ordering spots which suggests the presence of the $\delta^{\prime}$ precipitates in the as-quenched state. High resolution electron microscopy on an A1-9at.\%Li alloy aged for $1000 \mathrm{~h}$ at room temperature [23] shows the presence of $\delta^{\prime}$ spherical particles of about $5 \mathrm{~nm}$ average diameter.

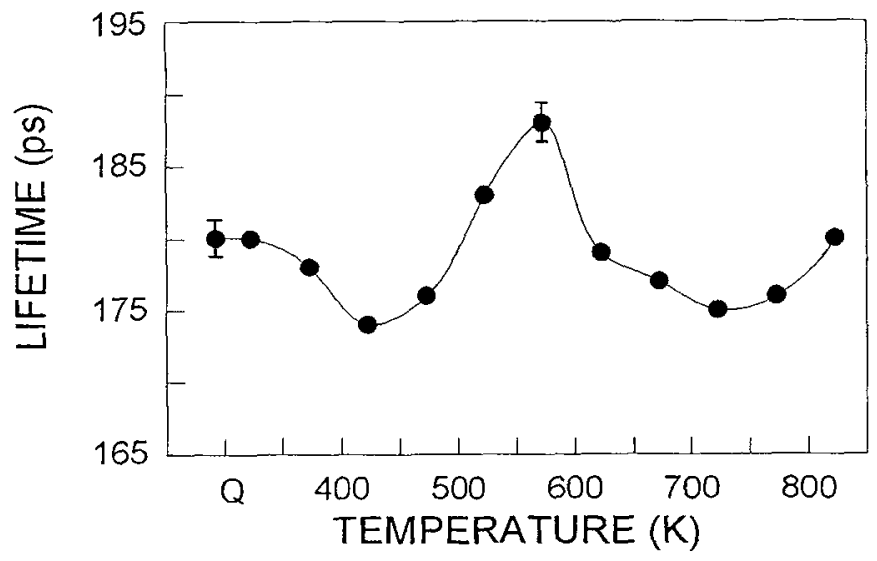

Fig.1. The evolution of the lifetime as a function of the annealing temperature for the AI-9.9at\%Li alloy

By comparing Fig. 1 with the previous results it is likely that in our as-quenched samples $\delta$ '-like regions are present. Because the lifetimes corresponding to positron annihilation from $\alpha$-phase $(\tau=175 \mathrm{ps})$ and $\delta^{\prime}$ precipitates $(\tau=189 \mathrm{ps})$ are so close to each other, the experimental lifetime spectrum can not be decomposed into two components. Therefore, the lifetime value of 180 ps obtained in the as-quenched samples indicates that positrons are annihilating from both $\alpha$-phase and $\delta$ '-like regions. However, the decrease of the lifetime up to $423 \mathrm{~K}$ clearly indicates the dissolution of these small $\delta^{\prime}$-like regions.

From the annealing temperature of $423 \mathrm{~K}$ on the positron lifetime starts to increase again to reach at $550 \mathrm{~K}$ the value of $189 \mathrm{ps}$ that corresponds to positron annihilation from the $\mathrm{L}_{2}$ structure of the $\delta^{\prime}$ precipitates. Thus, the lifetime increase indicates the growth of the $\delta^{\prime}$ precipitates after the transformation at $423 \mathrm{~K}$. Above $573 \mathrm{~K}$ the positron lifetime starts to decrease monotonically to reach at $723 \mathrm{~K}$ the value corresponding to positron annihilation from the $\alpha$-phase. The lifetime decrease is related to overcoming the solvus line between the $\delta^{\prime}\left(\mathrm{Al}_{3} \mathrm{Li}\right)$ and $\delta(\mathrm{AlLi})$ phase at these temperatures. The monotonous decreasing of the lifetime from the value corresponding to annihilation from $\delta^{\prime}$ precipitates, indicates their progressive dissolution. At $773 \mathrm{~K}$ the precipitates concentration is so low that the distance between them is much larger than the positron diffusion length, around $100 \mathrm{~nm}$ in $\mathrm{Al}$ at room temperature [16]; therefore, positrons annihilate from $\alpha$-phase. The solvus line between $\delta^{\prime}$ and $\delta$ phase indicates that $\delta$ precipitates should be present at these temperatures. However, $\delta$ precipitates nucleate preferably at grain boundaries [24], and grain sizes in this alloy are much larger than the positron diffusion length; therefore, $\delta$ precipitates can not be detected by positrons in the present conditions.

\subsection{Electron irradiation damage on the concentrated alloy}

Fig. 2 shows the evolution of the positron average lifetime for two Al-9,9at\%Li electron-irradiated alloys after different thermal treatments before irradiation as a function of the annealing temperature. When interpreting the results for the sample aged at $523 \mathrm{~K}$ for $4 \mathrm{~h}$ after being quenched from $823 \mathrm{~K}$ into water, it has to be pointed out that large $\delta^{\prime}$ precipitates are present. Since the post-irradiated lifetime value agrees the ones observed in $\mathrm{Al}-0,2 \mathrm{at} \% \mathrm{Li}$ and $\mathrm{Al}-1,7 \mathrm{at} \% \mathrm{Li}$ alloys [26], we can conclude that the defects trapping positrons must have a similar structure. However, the recovery stage is wider, as compared with the dilute alloys [26], extending up to $350-400 \mathrm{~K}$, indicating that some different mechanisms are involved in the radiation damage and recovery processes in the concentrated alloy. It is not unlikely that energetic electrons can produce high disorder in the $\delta^{\prime}$ particle lattices, producing partial or total precipitate dissolution. The displaced $\mathrm{Li}$ atoms and the radiation induced vacancies tend to form complexes where positrons are trapped, 
like in the diluted alloys. Reprecipitation takes place by mobile vacancies and solute atoms migration and diffusion, when the complexes dissociate. This could explain the extension of the recovery stage up to $350 \mathrm{~K}$. It is to be remarked that the lifetime value attained at $350 \mathrm{~K}$ is the same as the initial one $\tau \approx 180 \mathrm{ps,}$ lower than the value $\tau \approx 189 \mathrm{ps}$ attributed to the $\delta^{\prime}$ phase. The lower value can be explained if we assume that the $\delta^{\prime}$ volume fraction is not as high as to produce saturation trapping because the aging temperature for the Al-9.9at\% Li alloy prior to the irradiation is lower than the optimum one for the $\delta^{\prime}$ phase growth. Further annealing from $350 \mathrm{~K}$ increases the $\delta^{\prime}$ volume fraction and the lifetime tends to the saturation value $\tau \approx 189 \mathrm{ps}$ (see fig. 2).

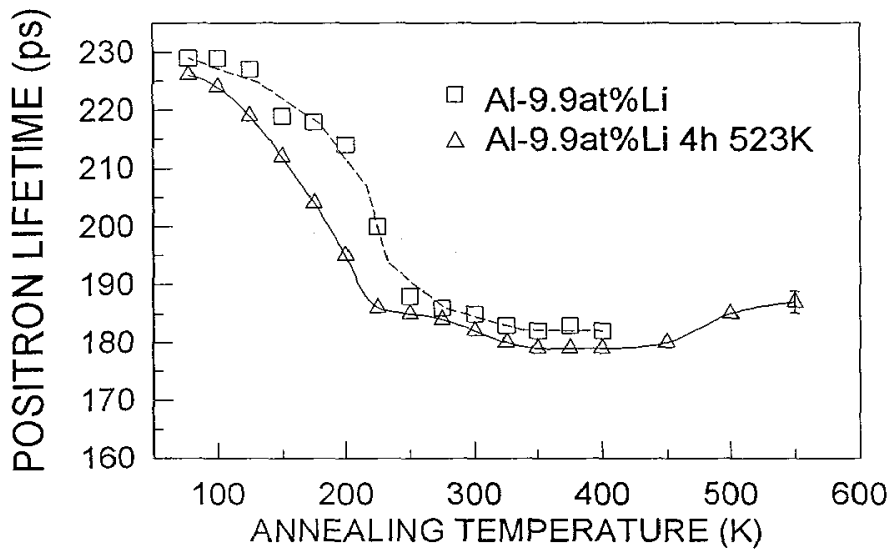

Fig.2. Evolution of the positron average lifetime as a function of the annealing temperature in electronirradiated () Al-9.9at\%Li quenched from $823 \mathrm{~K}$ into water and $(\Delta)$ Al-9.9at\% Li quenched from $823 \mathrm{~K}$ into water and aged at $523 \mathrm{Kfor} 4 \mathrm{~h}$.

The behaviour for the quenched $\mathrm{AI}-9.9$ at $\% \mathrm{Li}$ alloy does not exactly coincide with the recovery curve for the aged alloy. In fact the difference on the annealing behaviour for the as-quenched samples may be related to the existence in this sample of small $\delta^{\prime}$-like regions (see Fig.1) discussed in section 3.2. The radiation damage originates probably also in this case the dissolution of the $\delta^{\prime}$-like regions through the formation of Al vacancy-Li atoms complexes. The recovery processes involve presumably very similar progression to the one described for the aged alloy. However, since the precipitate structure is not the same, the curves shown in figure 2 do not exactly coincide.

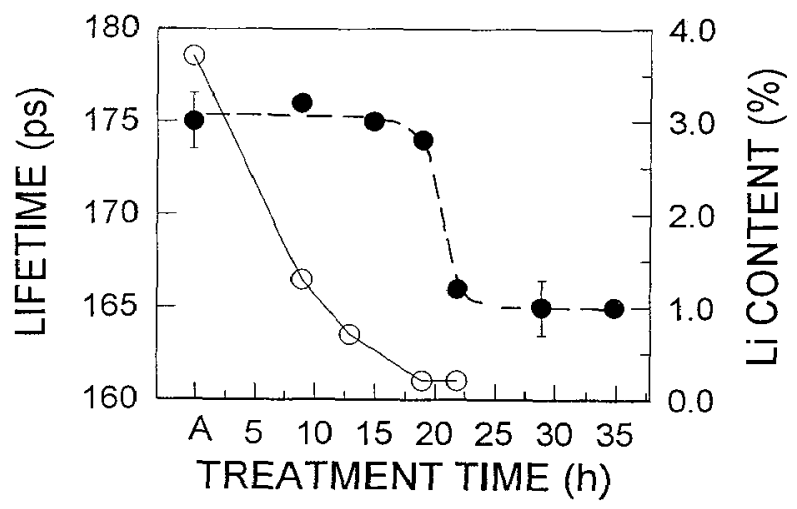

Fig.3. Evolution of the positron lifetime $(0)$ and of the Li concentration measured by AAS $(0)$ with the treatment time at $873 \mathrm{~K}$ in an $\mathrm{Al}-3.74 \mathrm{at} \% \mathrm{Li}$ alloy. 


\subsection{Lithium losses in diluted Al-Li alloys}

Fig. 3 shows the evolution of the room temperature lifetime (one-component analysis always gave satisfactory fits) as a function of the thermal treatment time at $873 \mathrm{~K}$ for dilute alloy 2 after its homogenisation at $823 \mathrm{~K}$ for $1 \mathrm{~h}$ (point marked $\mathrm{A}$ in the figure). Fig. $3 \mathrm{~b}$ monitors the decrease of the $\mathrm{Li}$ content for increasing treatment time for sample 2 by atomic absorption (AAS). The decrease in the lifetime above $15 \mathrm{~h}$ aging can be attributed to a $\mathrm{Li}$ loss. The final lifetime value, $\tau \approx 165 \mathrm{ps}$, which corresponds to the lifetime value measured in $\mathrm{Al}$ (see table 2), indicates that $\mathrm{Li}$ has completely disappeared from the samples or that its content has been lowered to a level where positrons are no more sensitive. The comparison of both figures 3(a) and 3(b) indicate that the lifetime value stays constant at 175ps and the positrons are not sensitive to the Li loss up to values as low as about $0.5 \mathrm{at} \% \mathrm{Li}$ content. However PAS seems to be very sensitive to low $\mathrm{Li}$ concentrations (between $0.5 \mathrm{at} \% \mathrm{Li}$ and $0.2 \mathrm{at} \% \mathrm{Li}$ ), where a drastic drop is observed in the lifetime while AAS data remain to a constant value of $0.2 \mathrm{at} \% \mathrm{Li}$.

It can be concluded that PAS can be used to monitor Li losses in Al-Li alloys, especially in the $\mathrm{Li}$ content range where a standard technique such as AAS is not sensitive.

\subsection{Lithium influence on defect nucleation in quenched diluted Al-Li alloys}

Fig. 4 shows the evolution of the room temperature lifetime parameters as a function of the aging time at $873 \mathrm{~K}$ for sample 2 . The sample was initially homogenised at $873 \mathrm{~K}$ for 1 hour. Thereafter, it was given cumulative heat treatments for several hours at $873 \mathrm{~K}$ ranging from 1 hour to 33 hours. Each aging at $873 \mathrm{~K}$ was followed by a quench at $273 \mathrm{~K}$. This combined heat treatment allows to follow the changes in the quenching behaviour induced by the Li losses produced after aging at $873 \mathrm{~K}$ for prolonged time periods and makes possible to study the role of $\mathrm{Li}$ in the nucleation of defects. Positron lifetime measurements were recorded at room temperature after each combined heat treatment. The point marked $A$ in the figure corresponds to the value in the as-quenched sample. The long component $\tau_{2}$ has an average value $\tau_{2}=270 \mathrm{ps}$ in the time range studied. The long component intensity, $I_{2}$, and the short component, $\tau_{1}$, start to change when the $\mathrm{Li}$ content decreases due to the losses experienced by the specimens when aging at $873 \mathrm{~K}$ (see section 3.3)). Therefore, the response of the alloys upon quenching is highly influenced by the Li content in the samples.

The one-trap model agrees the experimental $\tau$ values in the whole time interval studied, indicating the existence of only one kind of positron trap in these samples. The long value $\tau_{2}=270 \mathrm{ps}$ indicates positron trapping at vacancy type defects. Moreover, vacancies and vacancy clusters are retained up to 350 and $400 \mathrm{~K}$ if $\mathrm{Li}$ is added to pure $\mathrm{Al}[29,30]$. Recent calculations performed for vacancy-Li atoms complexes predict positron bound states for several configurations involving more than one vacancy [26], thus we suggest that the trapping signal characterised by the $\tau_{2}$ lifetime originates from small vacancy clusters stabilised by one or more $\mathrm{Li}$ atoms, that are in solid solution for $\mathrm{Li}$ concentrations up to $4.5 \mathrm{at} \%$ approximately [3]. The complex configuration and density depends only on the quenching conditions. If the $\mathrm{Li}$ concentration is higher than the vacancy concentration at thermal equilibrium at the temperature from which the samples are quenched, the complex size distribution will be the same at that temperature, regardless of the aging time. The vacancy concentration at $873 \mathrm{~K}$ can be estimated from the vacancy formation enthalpy and entropy taken from the literature [31] and is about $2.6 \times 10^{-4}$, well below $0.2 \mathrm{at} . \% \mathrm{Li}$, achieved after aging above $30 \mathrm{~h}$. Under these conditions, the above hypothesis holds and the size distribution of complexes will be the same in the whole time range studied. We can not assume that the small vacancy clusters are the only trap for positrons in the whole aging time range, because it would indicate that the concentration of vacancy-Li complexes increases when the $\mathrm{Li}$ concentration decreases (see the increase of the intensity $I_{2}$ in fig.4).

TEM observations performed in the Al-3.74at.\%Li alloy [27] show a density of small dislocation loops with a dislocation line density of $8.8 \times 10^{9} \mathrm{~cm}^{-2}$ (above the positron detection limit for these defects [28]) in an alloy aged for 5 hours at $873 \mathrm{~K}$ and subsequently quenched at $273 \mathrm{~K}$. No positron trapping at loops is to be expected in the long time aged samples (30h) since the estimated interloop distance is larger than the positron diffusion length [27].

The explanation of the positron data presented in Fig. 4 by a model that assumes two kinds of positron traps for short aging periods does not agree with the one trap model that satisfactorily fit the experimental results (see fig. 4) unless the lifetime associated to one of the traps is very close to the bulk lifetime for the dilute Al-Li alloys, which is $\tau_{b}=176 \mathrm{ps}$. This must be the case in the studied alloys, where the lifetime corresponding to annihilation in dislocation loops has to be very close to the one corresponding to loops in $\mathrm{Al}, i$. e. $\tau_{\mathrm{dl}} \approx 190 \mathrm{ps}[32,33]$. However, this model without competion between traps would indicate also that the vacancy-Li complexes density increases with aging time. Therefore, the only 
possibility left to explain the observed behaviour is to assume competition between vacancy clusters and dislocation loops. By recalling that the density of the vacancy-Li complexes must be the same, regardless of the $\mathrm{Li}$ content, and bearing in mind the high positron affinity for $\mathrm{Li}$ in an $\mathrm{Al}$ matrix, we propose to explain our results that the as-quenched samples contain both complexes and loops. The loops are decorated with $\mathrm{Li}$, as they are formed from the collapse of complexes containing $\mathrm{Li}$, whose dimensions are above the critical size to colapse into loops. In the aging time intervals where they can act as trapping centres for positrons, there is a competition between trapping at loops and at complexes, giving rise to an intensity associated to complexes, which is lower than the one that should be predicted by the two-trap model. The intensity associated to the loops is on the contrary enhanced due to the positron affinity to $\mathrm{Li}$, i.e., the positron is attracted to the Li-rich zones that decorate the loops but it is trapped at the open volume associated to the dislocation loops.

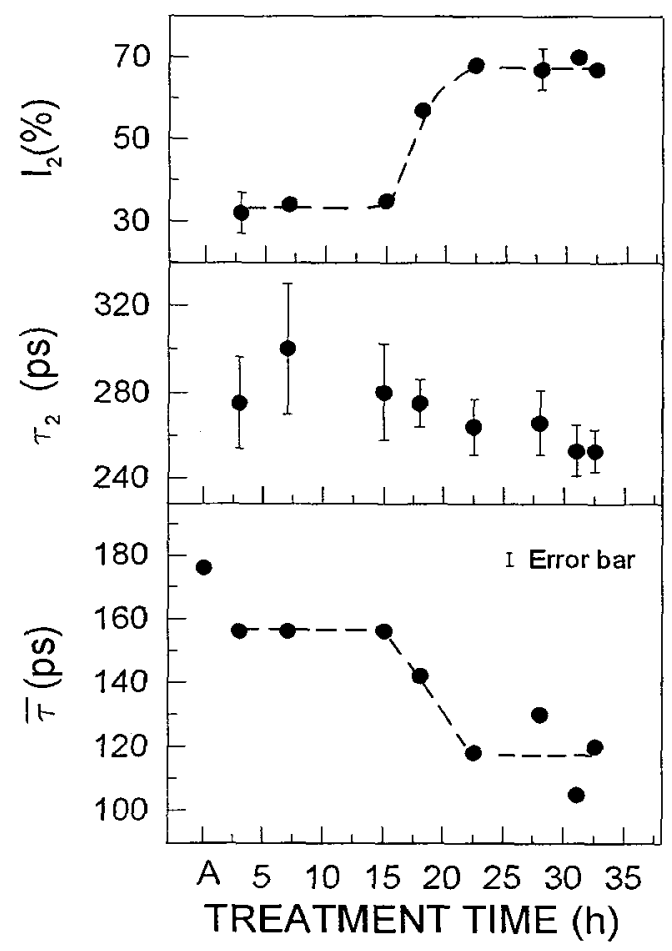

Fig.4. The evolution of the positron lifetime parameters as a function of the aging time at $873 \mathrm{~K}$ for the Al-3.74at\% Li alloy.

\section{CONCLUSIONS}

The positron lifetime measurements performed on concentrated Al-Li alloys in the as-quenched state, and supported by the measurements in electron irradiated alloys, suggest the presence of small $\delta^{\prime}$-like regions in the as-quenched state that dissolve at around $430 \mathrm{~K}$. The lifetime shows a peak at $550 \mathrm{~K}$ and $523 \mathrm{~K}$ for the $\mathrm{Al}-9.9 \mathrm{at} \% \mathrm{Li}$ and $\mathrm{Al}-8.6 \mathrm{at} \% \mathrm{Li}-0.04 \mathrm{at} \% \mathrm{Zr}$ respectively which coincides with the $\delta^{\prime}$-phase dissolution temperatures, in agreement with the Al-Li phase diagrams in the literature. These results show the high PAS sensitivity to detect the dissolution of $\delta$ precipitates.

The presence of $\mathrm{Zr}$ in the alloys does not affect the positron annihilation characteristics, due to the strong affinity of positrons to $\mathrm{Li}$. 
PAS can be used to monitor Li losses in Al- Li alloys, especially in the Li content range where a standard technique such as AAS is not sensitive.

The quenching to room temperature of $\mathrm{Al}-\mathrm{Li}$ alloys with a $\mathrm{Li}$ content below its solubility limit in $\mathrm{Al}$ gives rise to dislocation loops and vacancy-Li complexes formed by several vacancies and one or presumably more $\mathrm{Li}$ atoms, indicating that $\mathrm{Li}$ stabilises the vacancy clusters at room temperature. The loops, formed by the collapse of vacancy-Li clusters, are Li-rich zones highly attractive to positrons.

\section{Acknowledgments}

This work was supported by CICYT (Project № MAT91-0046)

\section{References}

[1] Lavernia.E.J. and Grant N.J.,J. Mat. Science, 22 (1987) 1521

[2] Lieblich M. and Torralba M., Rev Met. 26 (1990) 314

[3] Sung C.M., Chang H.M. and Williams D.B., Proc. of the 3rd Int. Conf. on Al-Li alloys, ed:

C.Baker, P.J. Gregson, S.J. Harris and C.J. Peel (The Institute of Metals, London 1986) p.337.

[4] Noble B. and Thompson G.E., Met. Sci.J. 5 (1971) 114

[5] Dlubek G., Krause H., Krause S. and Lademann P., Mat. Sci. Forum, 105-110 (1992) 977

[6] del Río J., Plazaola F. and de Diego N., Scripta Metall. Mater. 26 (1992) 1907.

[7] Puska M.J., Lanki P. and Nieminen R.M. J. Phys.: Condens. Matter 1 (1989) 6081

[8] Williams D.B., Proc. of the 5th Int. Conf. on Al-Li alloys (Williamsburg, Virginia, 1989), Vol. II.

[9] Kim N.J., Howe J.M. and Bodin E.G., J. de Physique 48 (1987) C3-457

[10] del Río J.and de Diego N., Phys.Stat. Sol. (a) 124 (1991) K141.

[11] Samuel F.H. and Champier G., J. Mat. Sci. 22 (1987) 3851

[12] Lock D.G. and West R.N.,J. Phys. F: Metal Physics 4 (1974) 2179

[13] Kubica P., Mckee B.T.A., Stewart A.T. and Stott M.J., Phys. Rev. B11 (1975) 11

[14] Stott M.J. and Kubica P., Phys. Rev. B11 (1975) 1

[15] Hono K. , Babu S.S., Hiraga K., Okano R. and Sakurai T., Acta Metall. Mater. 40 (1992) 3027

[16] Bergensen B., Pajanne E., Kubica P., Stott M.J. and Hodges C.H., Solid St. Comm. 15 (1974) 1377

[17] Nozato R. and Takai C., Trans. Japan Inst. Metals. 18 (1977) 679

[18] Papazian J.W., Sigli C. and Sánchez J.M., Scripta Metall. Mater. 20 (1986) 201

[19] Sato T. and Kamio A.,Mat. Trans. Japan Inst. Metals. 31 (1990) 25

[20] Sigli C. and Sánchez J.M., Acta Metall. 34 (1986) 1021

[21] Khachaturyan A.G., Lindsay T.F. and Morris J.W., Metalll. Trans. 19A (1988) 249

[22] del Río J., Plazaola F. and de Diego N., Phil. Magazine.. (in press).

[23] Lendvai J. , Wunderlich W. and Gudlat H.J., Phil. Magazine. 67A (1993) 99

[24] Venables D., Christodaulou L. and Pickens J.R., Scripta Metall. 17 (1983) 1263

[25] Gayle F.W. and Vander Sande J.B., Scripta Metall. 18 (1984) 473

[26] del Rio J., Plazaola F., de Diego N. and Moser P., Phys. Rev. 47B (1993) 2453

[27] del Rio J., Plazaola F. and de Diego N., Acta Metall. (in press)

[28] Byrne J. G., Dislocations in Solids, 6 (1983) p.63 (ed. F.R.N. Navarro), North Holland.

[29] de Diego N., del Rio J., Segers D., Dorikens-Vanpraet L. and Dorikens M., Phys. Rev. 48B (1993) 6781

[30] Leighly H.P., Coleman P.G. and West R.N., Positron Annihilation (ed. L. Dorikens-Vanpraet, D. Segers and M. Dorikens), World Sci. Publ. (1989) p.470

[31] Wollenberger H.J., Physical Metallurgy (ed. R.W. Cahn and P. Haasen), North-Holland (1983) p.1146,

[32] Mäkinen S., Häkkinen H. and Manninen M., Phys. Sci. 33T (1990) 216

[33] Shirai Y., Matsumoto K., Kawagucchi G. and Yamaguchi M., Mat. Sci. Forum 105-110 (1992) 1225 